\title{
REVIEW
}

\section{Utility of Saxagliptin in the Treatment of Type 2 Diabetes: Review of Efficacy and Safety}

Rajeev Jain

To view enhanced content go to www.advancesintherapy.com

Received: September 4, 2015 / Published online: November 17, 2015

(c) The Author(s) 2015. This article is published with open access at Springerlink.com

\section{ABSTRACT}

Introduction: Type 2 diabetes mellitus (T2DM) is a complex disease in which multiple organs and hormones contribute to the pathogenesis of disease. The intestinal hormone, glucagon-like peptide-1 (GLP-1), secreted in response to nutrient ingestion, increases insulin secretion from pancreatic $\beta$-cells and reduces glucagon secretion from pancreatic $\alpha$-cells. GLP-1 is inactivated by the dipeptidyl peptidase-4 (DPP-4) enzyme. Saxagliptin is a DPP-4 inhibitor that prevents the degradation of endogenous GLP-1 and prolongs its actions on insulin and glucagon secretion. This article reviews the efficacy and safety of saxagliptin in patients with T2DM.

Methods: A PubMed literature search was conducted to identify relevant, peer-reviewed saxagliptin clinical trial articles published between January 2008 and June 2015.

Electronic supplementary material The online version of this article (doi:10.1007/s12325-015-0262-9) contains supplementary material, which is available to authorized users.

R. Jain $(\bowtie)$

Aurora Advanced Healthcare, Milwaukee, WI, USA

e-mail: Rajeev.Jain@aurora.org
Search terms included "saxagliptin" and "DPP-4 inhibitors".

Results: In clinical trials, saxagliptin significantly improved glycemic control when used as monotherapy or as add-on therapy to other antidiabetes agents and was associated with a low risk of hypoglycemia. In a large cardiovascular (CV) outcomes trial (SAVOR) in patients with T2DM and with established CV disease or multiple $\mathrm{CV}$ risk factors, saxagliptin neither increased nor decreased $\mathrm{CV}$ risk compared with placebo as assessed by the composite end point of death from CV causes, nonfatal myocardial infarction, or nonfatal stroke. Unexpectedly, more patients in the saxagliptin (3.5\%) than in the placebo group $(2.8 \%)$ were hospitalized for heart failure.

Conclusion: Saxagliptin demonstrated statistically significant and clinically meaningful improvements in glycemic control and a low risk of hypoglycemia in patients with T2DM. However, this positive profile needs to be tempered by the observation of an increased risk of hospitalization for heart failure in the SAVOR trial. Results from ongoing CV outcome trials with other DPP-4 inhibitors may provide additional data on how best to manage patients with T2DM who are at risk for heart failure. 
Funding: AstraZeneca LP.

Keywords: Antidiabetes drugs; Dipeptidyl peptidase-4 inhibitor; Saxagliptin; Type 2 diabetes mellitus

\section{INTRODUCTION}

Diabetes, both diagnosed and undiagnosed, affects an estimated 382 million people worldwide [1] and 29.1 million people in the United States (US) [2]. Type 2 diabetes mellitus (T2DM) accounts for up to $95 \%$ of diagnosed cases of diabetes [2], and the International Diabetes Federation estimates that $46 \%$ of all prevalent cases are undiagnosed [1]. T2DM is strongly associated with obesity, physical inactivity, and dyslipidemia [3]. It is becoming evident that there is also a genetic component to T2DM [4], and although the genetics are not well understood, individuals of certain racial/ ethnic backgrounds and those with a family history of diabetes are at increased risk for development of T2DM [2, 5]. Despite the availability of various classes of antidiabetes agents, nearly half of patients fail to achieve recommended glycemic targets [6, 7]. Poorly controlled T2DM often leads to microvascular (e.g., retinopathy, neuropathy, and nephropathy) and macrovascular [coronary heart disease, stroke, myocardial infarction (MI)] complications [8], and cardiovascular (CV) disease is the major cause of death in individuals with diabetes [9].

It is now recognized that T2DM is a chronic, progressive disease and that multiple organs and hormones contribute to its pathogenesis. Regulation of glucose homeostasis is tightly controlled by a feedback loop involving pancreatic $\beta$-cells, $\alpha$-cells, and insulin-sensitive tissues such as the liver, muscle, and fat [10].
Impairments in glycemic control are evident long before the diagnosis of overt T2DM [11]. As discussed by DeFronzo [11], in addition to $\beta$-cells, liver, and muscle, pancreatic $\alpha$-cells (increased glucagon secretion), fat cells (increased lipolysis), gastrointestinal tract (incretin deficiency), kidney (increased glucose reabsorption), and brain (neurotransmitter dysfunction) are involved in the pathogenesis of T2DM (Fig. 1). This "ominous octet" not only puts into perspective the complexity of T2DM but also presents therapeutic targets to explore to improve glycemic control in T2DM.

\section{Incretin Biology}

Drugs that act on the incretin system are among the newer antidiabetes therapies. The incretin effect refers to the observation made more than 50 years ago that oral glucose produced a greater increase in plasma insulin concentrations than did an isoglycemic intravenous glucose infusion [12]. At that time, it was hypothesized that a factor(s) released from the gastrointestinal tract in response to oral glucose could be responsible for increased insulin secretion [12]. Subsequently, it

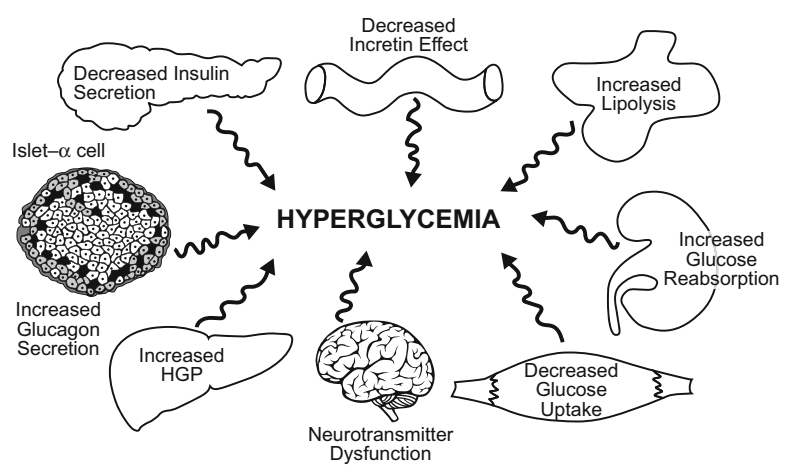

Fig. 1 The complexity of type 2 diabetes pathophysiology. $H G P$ hepatic glucose production. Reproduced with permission from DeFronzo [11] 
was shown that two intestinal hormones, glucose-dependent insulinotropic polypeptide (GIP) and glucagon-like peptide-1 (GLP-1), were responsible for the potentiated insulin release in response to nutrient ingestion [13]. GLP-1 and GIP are secreted from cells in the intestine in response to food ingestion and act on pancreatic $\beta$-cells via distinct receptors to stimulate the release of insulin in a glucose-dependent manner. In healthy individuals, up to $60 \%$ of insulin secretion following a meal is due to the actions of the incretin hormones [14]. GLP-1 also inhibits glucagon secretion from pancreatic $\alpha$-cells in a glucose-dependent manner, regulates gastric emptying, and acts on the central nervous system to reduce food intake [13]. Although meal-stimulated concentrations of both GIP and GLP-1 are variable (can be normal or elevated) in patients with T2DM [10, 12], the insulinotropic response to GIP is substantially reduced, whereas the insulinotropic response to pharmacologic doses of GLP-1 is retained. Because the response to GLP-1 remains relatively intact in patients with T2DM, incretin-based therapies have focused on GLP-1 receptor agonists or on prolonging the half-life of endogenous GLP-1 by inhibiting dipeptidyl peptidase-4 (DPP-4), the enzyme responsible for the degradation of GLP-1 and GIP [15].

Saxagliptin is a DPP-4 inhibitor approved in the US, European Union, and elsewhere for the treatment of T2DM in adults. The objective of this article is to discuss the utility of saxagliptin for the treatment of T2DM by reviewing published efficacy and safety data from clinical trials.

\section{METHODS}

Articles for this narrative, nonsystematic review were obtained by reviewing published clinical trial data. A PubMed literature search was conducted to identify relevant, peer-reviewed clinical trial articles published between January 2008 and June 2015 related to saxagliptin. Search terms included "saxagliptin" and "DPP-4 inhibitors." In addition, the bibliographies of retrieved articles were reviewed and key references were obtained. Only randomized phase 3 and 4 trials of saxagliptin with a primary study period of at least 24 weeks and reporting findings for saxagliptin 2.5 and $5 \mathrm{mg} /$ day doses were selected for this review. A total of 14 articles on saxagliptin met these inclusion criteria. This article is based on previously conducted studies and does not involve any new studies of human or animal subjects performed by the author.

\section{RESULTS}

\section{Short-Term (24-Week) Data}

\section{Placebo-Controlled Monotherapy Studies with Saxagliptin}

Four studies examined the efficacy and safety of saxagliptin (2.5 and/or $5 \mathrm{mg} /$ day $)$ as monotherapy in treatment-naïve adults with T2DM not controlled with diet and exercise alone [16-19]. In these trials, 24 weeks of saxagliptin treatment was associated with significantly greater reductions in glycated hemoglobin (HbA1c) compared with placebo. Differences vs placebo in $\mathrm{HbA1c}$ reduction ranged from $-0.45 \%$ to $-0.65 \%$. Improvements in fasting plasma glucose (FPG) and postprandial glucose (PPG) measured 120 min after a test meal were also noted in these monotherapy studies. In treatment-naïve patients from India [17] and Asia (approximately 59\% Chinese) [18], saxagliptin improved glycemic measures to a similar extent 
as seen in patients primarily from Western countries (Table 1). Across the 4 monotherapy trials, the proportion of patients achieving a therapeutic goal of $\mathrm{HbA} 1 \mathrm{c}<7 \%$ ranged from $22.1 \%$ to $45.8 \%$ with saxagliptin compared with $13.3-35.3 \%$ with placebo (Table 1). Changes in body weight were small and similar with saxagliptin and placebo. Improvement from baseline in $\beta$-cell function, as assessed by homeostasis model assessment of $\beta$-cell function (HOMA-2 $\beta$ ) [20], was greater with saxagliptin (range 12.1-14.6\%) than with placebo (5.4-8.1\%) [18, 19]. In all studies, proportions of patients reporting hypoglycemia were low and similar between saxagliptin (0-8.1\%) and placebo (0-6.3\%) treatment arms. Confirmed hypoglycemia (fingerstick glucose $\leq 50 \mathrm{mg} / \mathrm{dL}$ and associated symptoms) with saxagliptin or placebo was rare $(\leq 1.4 \%$; Table 2$)$.

\section{Saxagliptin With Metformin}

Saxagliptin as add-on to metformin in patients with inadequate glycemic control on metformin was evaluated in 3 trials [21-23] and as initial combination therapy with metformin in treatment-naïve patients in 1 trial [24]. In these trials, there were significantly greater reductions in HbA1c $(-0.42 \%$ to $-0.83 \%)$ [21-24], FPG, and PPG [21, 23, 24] vs placebo when saxagliptin (2.5 and/or $5 \mathrm{mg} /$ day) was added to metformin. Saxagliptin was effective in Asian patients (approximately $57 \%$ Chinese) [23] and in patients from Western countries in improving glycemic control (Table 1). In metformin-tolerant patients, saxagliptin added to a fixed dose of metformin (1500 mg/day) produced similar reductions in HbA1c and FPG compared with a 2-step uptitration of metformin to a maximum of $2500 \mathrm{mg} /$ day (Table 1) [22]. Within each of the 4 studies, more patients achieved $\mathrm{HbA1c}<7 \%$ with saxagliptin (37.1-60.3\%) than with comparator
(16.6-41.1\%), and there were greater increases from baseline in HOMA-2 $\beta$ with saxagliptin (4.7-33.0\%) than with comparator $(2.3 \%-22.6 \%)$. Small reductions in body weight $(<2 \mathrm{~kg})$ were observed in all studies and were similar between saxagliptin and comparator groups.

Hypoglycemia was reported in $1.4-7.8 \%$ and $1.4-5 \%$ of patients receiving saxagliptin and comparator, respectively. Confirmed hypoglycemia occurred in $\leq 1.4 \%$ of patients in all treatment groups (Table 2).

\section{Saxagliptin Add-On to Other Antidiabetes Agents}

Add-on of saxagliptin to other antidiabetes agents such as a thiazolidinedione (TZD) [25], a sulfonylurea [26], or insulin (with or without metformin) [27] produced significantly greater reductions in $\mathrm{HbA1c}(-0.36 \%$ to $-0.72 \%)$, PPG, and in 2 studies $[25,26]$, FPG, compared with placebo (Table 1).

In the add-on to TZD study [25], significantly more patients receiving saxagliptin (41.8-42.2\%) achieved HbA1c $<7 \%$ compared with placebo (25.6\%). In addition, the change from baseline in HOMA-2 $\beta$ was greater with saxagliptin add-on to TZD than placebo (10-11\% vs $2.9 \%$ ) [25]. The proportions of patients with reported $(2.7-4.1 \%$ vs $3.8 \%)$ and confirmed hypoglycemia (0-0.5\% vs $0 \%$ ) were similar with saxagliptin add-on to TZD and placebo (Table 2).

In patients treated with saxagliptin add-on to glyburide vs those receiving placebo plus uptitrated glyburide, 22.4-22.8\% achieved HbA1c $<7 \%$ with saxagliptin compared with 9.1\% with uptitrated glyburide $(P<0.0001)$ [26]. HOMA-2 $\beta$ increased to a similar extent (7.6-9.5\% with saxagliptin vs $4.6 \%$ with uptitrated glyburide), and there were small increases $(\leq 0.8 \mathrm{~kg})$ in body weight in all 
Table 1 Difference versus placebo or comparator in change from baseline in HbAlc, FPG, and PPG with saxagliptin in 24-week phase 3 clinical trials

\begin{tabular}{|c|c|c|c|c|c|c|c|}
\hline & \multirow{2}{*}{ Saxagliptin } & \multicolumn{2}{|l|}{ HbAlc (\%) } & \multicolumn{2}{|c|}{ FPG $(\mathrm{mg} / \mathrm{dL})$} & \multicolumn{2}{|c|}{ PPG (mg/dL) } \\
\hline & & $2.5 \mathrm{mg} / \mathrm{day}$ & $5 \mathrm{mg} / \mathrm{day}$ & $2.5 \mathrm{mg} /$ day & $5 \mathrm{mg} / \mathrm{day}$ & $2.5 \mathrm{mg} / \mathrm{day}$ & $5 \mathrm{mg} / \mathrm{day}$ \\
\hline \multicolumn{8}{|c|}{ SAXA vs PBO, treatment-naïve patients } \\
\hline NCT00121641 [19] & Difference vs $\mathrm{PBO}$ & -0.62 & -0.65 & -21 & -15 & -39 & -37 \\
\hline$N=401^{\mathrm{a}}$ & $P$ value & $<0.0001$ & $<0.0001$ & 0.0002 & 0.007 & 0.0007 & 0.0009 \\
\hline NCT00316082 [16] & Difference vs $\mathrm{PBO}$ & -0.45 & -0.40 & -15 & -14 & -30 & -31 \\
\hline$N=365^{\mathrm{a}}$ & $P$ value & 0.002 & 0.006 & 0.020 & 0.027 & 0.019 & 0.019 \\
\hline NCT00698932 [18] & Difference vs $\mathrm{PBO}$ & - & -0.50 & - & -13 & - & -24 \\
\hline$N=568^{\mathrm{a}}$ & $P$ value & & $<0.0001$ & & $<0.0001$ & & NT \\
\hline NCT00918879 [17] & Difference vs $\mathrm{PBO}$ & - & -0.46 & - & -10 & - & - \\
\hline$N=213^{\mathrm{a}}$ & $P$ value & & 0.0011 & & NS & & \\
\hline \multicolumn{8}{|c|}{ SAXA vs $\mathrm{PBO}$, add-on to MET } \\
\hline NCT00121667 [21] & Difference vs $\mathrm{PBO}$ & -0.73 & -0.83 & -16 & -23 & -44 & -40 \\
\hline$N=743^{\mathrm{a}}$ & $P$ value & $<0.0001$ & $<0.0001$ & $<0.0001$ & $<0.0001$ & $<0.0001$ & $<0.0001$ \\
\hline NCT00661362 [23] & Difference vs $\mathrm{PBO}$ & - & -0.42 & - & -10 & - & -18 \\
\hline$N=570^{\mathrm{a}}$ & $P$ value & & $<0.0001$ & & 0.0002 & & NT \\
\hline NCT00327015 [24] & Difference vs $\mathrm{PBO}$ & - & -0.5 & - & -13 & - & -41 \\
\hline$N=1306^{\mathrm{a}}$ & $P$ value & & $<0.0001$ & & 0.0002 & & $<0.0001$ \\
\hline NCT01006590 [22] & Difference vs PBO & - & -0.10 & - & 0 & - & - \\
\hline$N=286^{\mathrm{a}}$ & $P$ value & & NS & & NT & & \\
\hline \multicolumn{8}{|c|}{ SAXA vs PBO add-on to TZD } \\
\hline NCT00295633 [25] & Difference vs $\mathrm{PBO}$ & -0.36 & -0.63 & -11 & -14 & -36 & -5 \\
\hline$N=565^{\mathrm{a}}$ & $P$ value & 0.0007 & $<0.0001$ & 0.005 & 0.0005 & $<0.0001$ & $<0.0001$ \\
\hline \multicolumn{8}{|c|}{ SAXA vs $\mathrm{PBO}$, add-on to insulin \pm MET } \\
\hline NCT00757588 [27] & Difference vs PBO & - & -0.41 & - & -4 & - & -23 \\
\hline$N=455^{\mathrm{a}}$ & $P$ value & & $<0.0001$ & & NS & & 0.0016 \\
\hline \multicolumn{8}{|c|}{ SAXA vs PBO, add-on to glyburide } \\
\hline NCT00313313 [26] & Difference vs $\mathrm{PBO}$ & -0.62 & -0.72 & -8 & -11 & -39 & -42 \\
\hline$N=768^{\mathrm{a}}$ & $P$ value & $<0.0001$ & $<0.0001$ & 0.02 & 0.002 & $<0.0001$ & $<0.0001$ \\
\hline \multicolumn{8}{|c|}{ SAXA vs PBO, add-on to MET $+\mathrm{SU}$} \\
\hline NCT01128153 [28] & Difference vs $\mathrm{PBO}$ & - & -0.66 & - & -8 & - & -17 \\
\hline$N=257^{\mathrm{a}}$ & $P$ value & & 0.0001 & & NS & & 0.03 \\
\hline
\end{tabular}


Table 1 continued

\begin{tabular}{|c|c|c|c|c|c|c|c|}
\hline & \multirow[t]{2}{*}{ Saxagliptin } & \multicolumn{2}{|l|}{ HbA1c (\%) } & \multicolumn{2}{|c|}{ FPG $(\mathbf{m g} / \mathbf{d L})$} & \multicolumn{2}{|c|}{ PPG (mg/dL) } \\
\hline & & $2.5 \mathrm{mg} / \mathrm{day}$ & $5 \mathrm{mg} / \mathrm{day}$ & $2.5 \mathrm{mg} / \mathrm{day}$ & $5 \mathrm{mg} / \mathrm{day}$ & $2.5 \mathrm{mg} / \mathrm{day}$ & $5 \mathrm{mg} / \mathrm{day}$ \\
\hline \multicolumn{8}{|c|}{ SAXA vs glipizide, add-on to MET (noninferiority trial) ${ }^{\mathrm{b}}$} \\
\hline NCT00575588 [29] & $\begin{array}{c}\text { Difference vs } \\
\text { glipizide }\end{array}$ & - & 0.06 & - & 6 & - & -21 \\
\hline$N=858^{\mathrm{a}}$ & $P$ value & & NS & & NT & & NT \\
\hline
\end{tabular}

treatment groups. Hypoglycemia was reported in $13.3-14.6 \%$ of patients taking saxagliptin and $10.1 \%$ of patients receiving uptitrated glyburide. Confirmed hypoglycemia was infrequent in all treatment groups (saxagliptin, 0.8-2.4\%; uptitrated glyburide, 0.7\%; Table 2).

In patients with T2DM poorly controlled with insulin ( \pm metformin), the addition of saxagliptin increased the proportion of patients reaching HbA1c $<7 \%$ after 24 weeks (17.3\%) compared with placebo (6.7\%) [27]. There were small increases in body weight $(\leq 0.4 \mathrm{~kg})$ in both treatment groups. The change in daily insulin dose required by patients to maintain prespecified FPG concentrations was greater in patients receiving placebo $(5.0 \mathrm{U} /$ day than in those receiving saxagliptin (1.7 U/day). A similar proportion of patients in the saxagliptin and placebo groups reported hypoglycemic events $(18.4 \%$ and $19.9 \%)$ and confirmed hypoglycemia (5.3\% and 3.3\%; Table 2).

In patients with inadequate glycemic control taking metformin plus a sulfonylurea, the addition of saxagliptin ( $5 \mathrm{mg}$ /day) resulted in a significantly greater reduction from baseline in HbA1c vs placebo $(-0.66 \%)$ at 24 weeks [28]. The reduction in PPG, but not FPG, was also greater with saxagliptin compared with placebo.
In addition, a greater proportion of patients achieved HbA1c $<7 \%$ with saxagliptin (30.7\%) vs placebo $(9.4 \% ; P<0.0001$; Table 1$)$. There were small changes in body weight with saxagliptin $(0.2 \mathrm{~kg})$ and placebo $(-0.6 \mathrm{~kg})$. Reported and confirmed hypoglycemic events were similar in the two treatment groups (Table 2).

Saxagliptin was also compared with glipizide as add-on therapy to metformin [29]. After 52 weeks of treatment, saxagliptin $(5 \mathrm{mg} /$ day $)$ was noninferior to glipizide in reducing $\mathrm{HbA} 1 \mathrm{c}$ $(-0.74 \%$ vs $-0.80 \%$; Table 1$)$, and similar proportions of patients achieved HbA1c $\leq 6.5 \%$ $(35.9 \%$ vs $34.3 \%)$. There was a significant $(P<0.0001)$ reduction in body weight with saxagliptin of $-1.1 \mathrm{~kg}$ vs an increase of $1.1 \mathrm{~kg}$ with glipizide. Reported hypoglycemia was more than tenfold higher in the glipizide group (36.3\%) vs the saxagliptin group (3.0\%). No patients had confirmed hypoglycemia with saxagliptin compared with 38 patients (8.8\%) in the glipizide group (Table 2).

\section{Dual Add-On of Saxagliptin and Dapagliflozin to Metformin}

In contrast to the traditional sequential addition of single oral antidiabetes agents to metformin, a recent clinical trial assessed the 


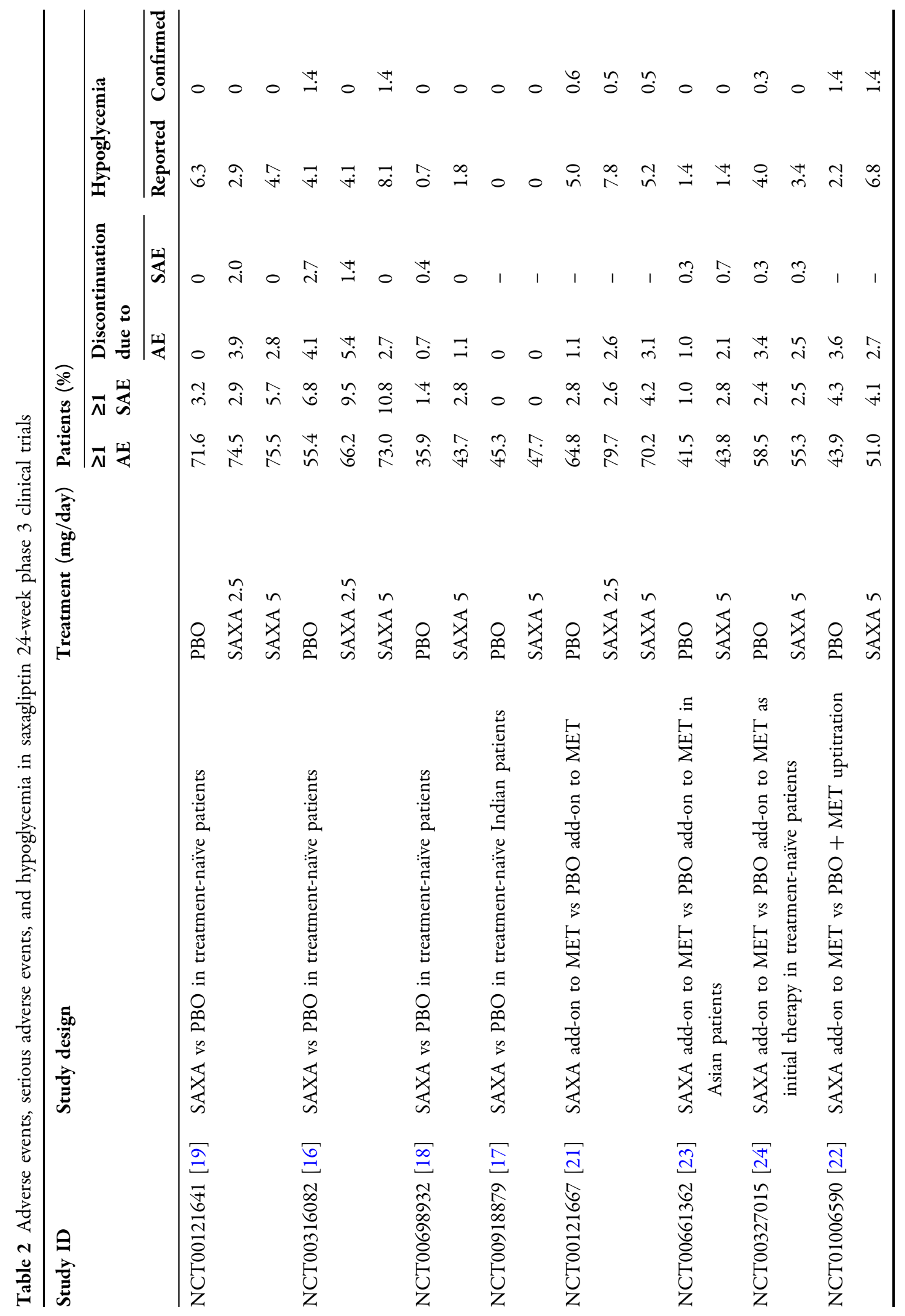




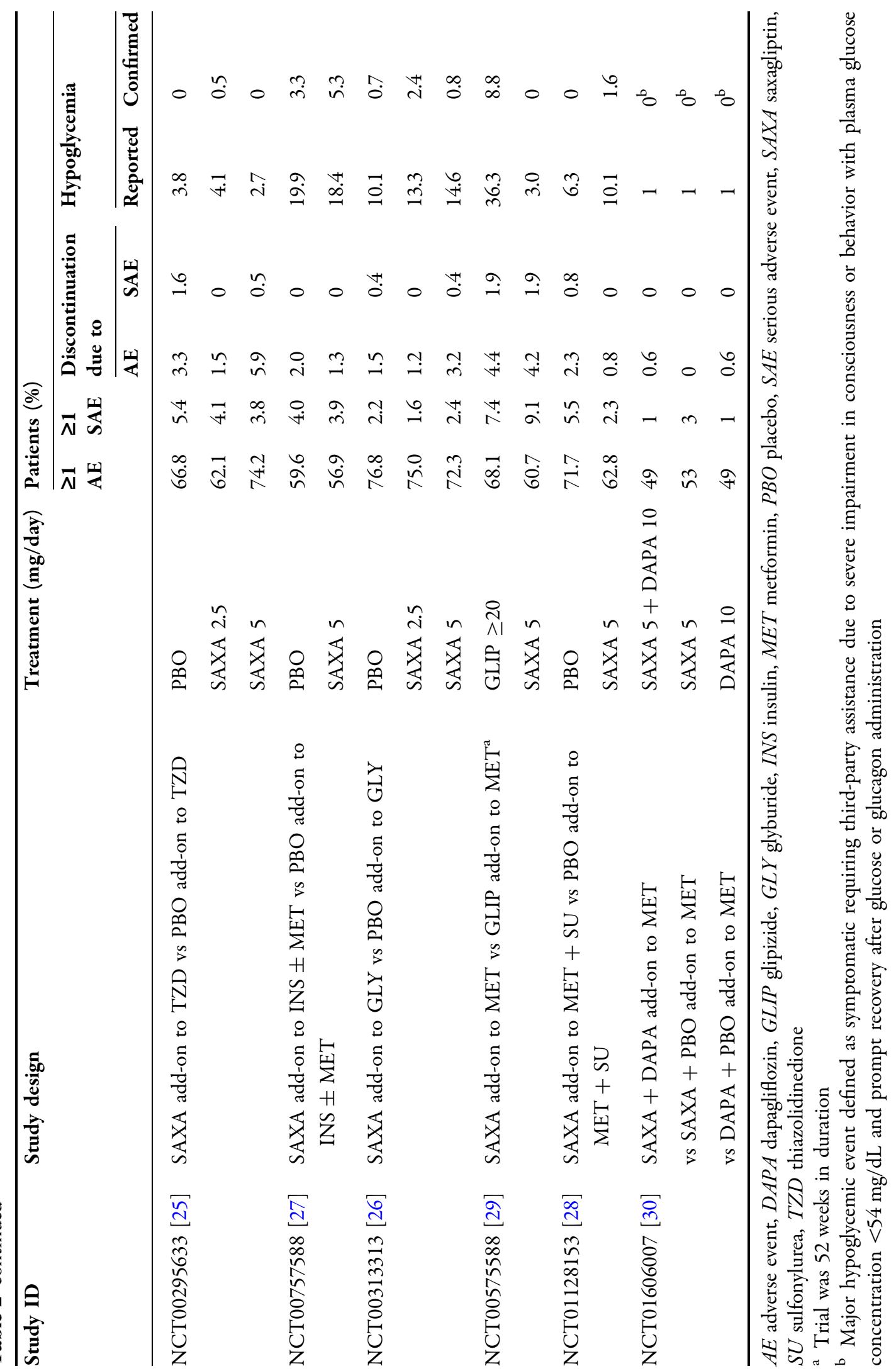


efficacy and safety of dual add-on of saxagliptin ( $5 \mathrm{mg} /$ day) plus the sodium-glucose cotransporter 2 inhibitor, dapagliflozin (10 mg/day), to metformin compared with saxagliptin add-on or dapagliflozin add-on alone to metformin in patients with T2DM poorly controlled with metformin monotherapy [30]. After 24 weeks, the adjusted mean change from baseline in HbA1c was significantly greater with saxagliptin/dapagliflozin/metformin $(-1.47 \%)$ than with saxagliptin/metformin $(-0.88 \%)$ or dapagliflozin/metformin (-1.20\%; Table 3). The adjusted mean reduction from baseline in FPG was greater in the triple therapy group $(-38 \mathrm{mg} / \mathrm{dL})$ than in the saxagliptin/metformin group ( $-14 \mathrm{mg} / \mathrm{dL}$ ) but similar to that observed in the dapagliflozin/metformin group $(-32 \mathrm{mg} / \mathrm{dL})$. Likewise, the reduction in PPG was also significantly greater with saxagliptin/dapagliflozin/metformin $(-80 \mathrm{mg} / \mathrm{dL})$ compared with saxagliptin/metformin $(-36 \mathrm{mg} / \mathrm{dL})$, but not compared with dapagliflozin/metformin $\quad(-70 \mathrm{mg} / \mathrm{dL})$. The proportion of patients achieving HbA1c $<7 \%$ at week 24 with saxagliptin/dapagliflozin/ metformin (41\%) was approximately double that seen with saxagliptin/metformin (18\%) or dapagliflozin/metformin (22\%). Body weight was reduced in patients receiving saxagliptin/dapagliflozin/metformin $\quad(-2.1 \mathrm{~kg})$ and dapagliflozin/metformin (-2.4 kg), whereas no change was noted in patients on saxagliptin/metformin (Table 3). Hypoglycemic events were infrequent and similar across treatment groups (1\%; Table 2$)$.

\section{Long-Term Data}

The safety and efficacy of most DPP-4 inhibitors have been evaluated for up to 2 years [31-34], but data over longer periods of time are lacking.
Saxagliptin is the only DPP-4 inhibitor with published data through 4 years of treatment [35].

In a long-term extension of the saxagliptin add-on to metformin study [21], HbA1c was reduced from baseline to 154 weeks by $0.4 \%$ with saxagliptin 2.5 and $5 \mathrm{mg}$ /day compared with an increase of $0.1 \%$ with placebo [35]. Also, a greater proportion of patients achieved HbA1c $<7 \%$ with saxagliptin (19-24\%) than with placebo (13\%). In this study and in a long-term extension of the saxagliptin monotherapy study [19], there were no increases in body weight, no increased risk of hypoglycemia, and no new safety findings for up to 4 years of treatment [35].

In a long-term extension of the saxagliptin plus metformin initial combination trial [24], the change from baseline to 76 weeks in HbA1c with saxagliptin $5 \mathrm{mg}$ /day plus metformin was $-2.31 \%$ vs $-1.79 \%$ with placebo plus metformin, changes that were similar to those seen at 24 weeks [36]. In addition, a greater proportion of patients achieved $\mathrm{HbA} 1 \mathrm{c}<7 \%$ after 76 weeks with saxagliptin add-on (51.1\%) than with placebo (34.7\%) add-on to metformin. Reductions from baseline in FPG and PPG at 76 weeks were also greater with saxagliptin vs placebo. The proportion of patients discontinued or rescued for lack of glycemic control by week 76 estimated by Kaplan-Meier analysis was lower in the saxagliptin plus metformin group (27.8\%) compared with the placebo plus metformin group (41.9\%). The overall safety profile over the 76 weeks was similar between treatment groups.

Sustained efficacy of saxagliptin vs placebo was also observed in a long-term extension of the add-on to TZD study [25]. After 76 weeks of treatment, the change from baseline in HbA1c was $-0.59 \%$ and $-1.09 \%$ with saxagliptin 2.5 


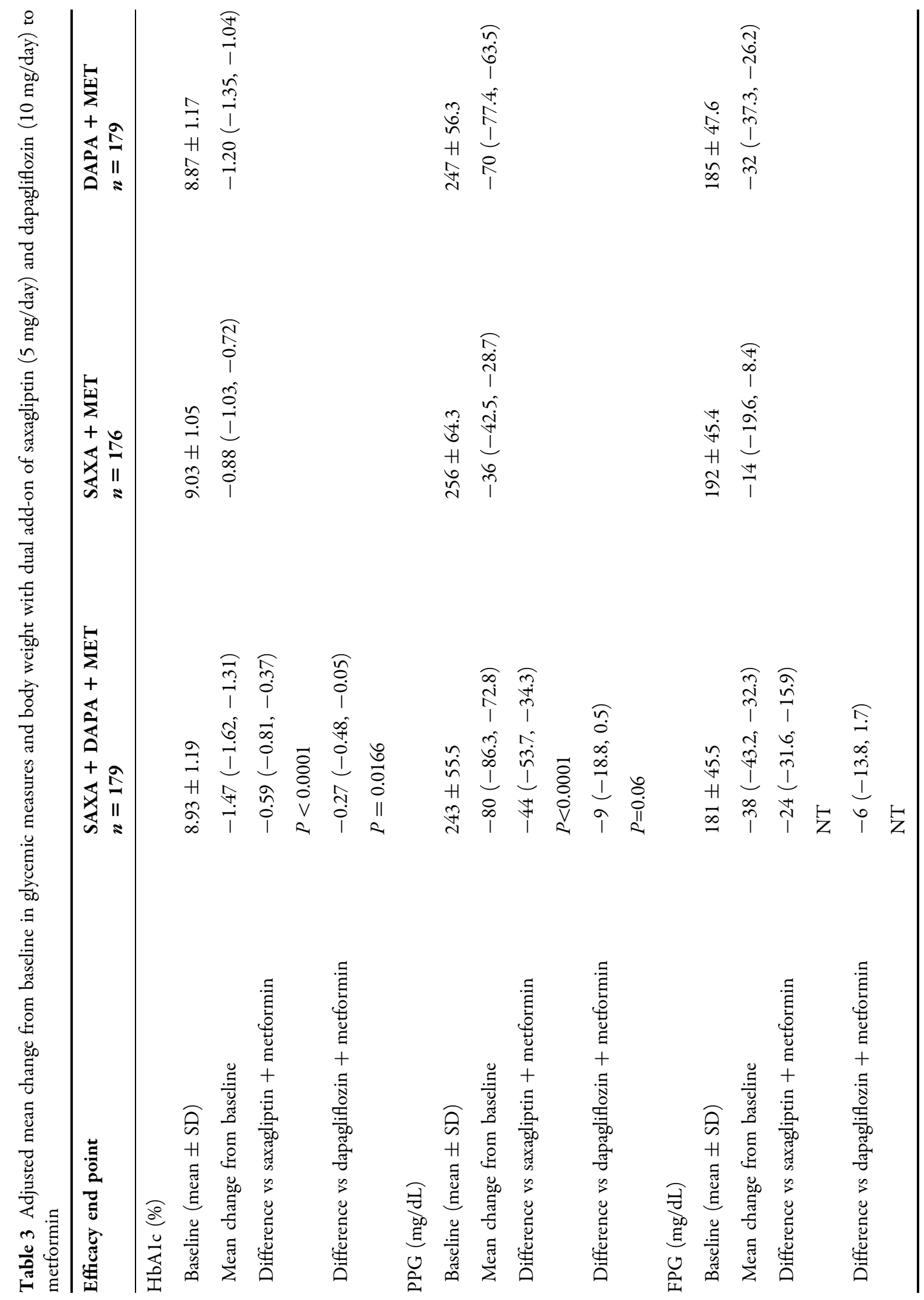




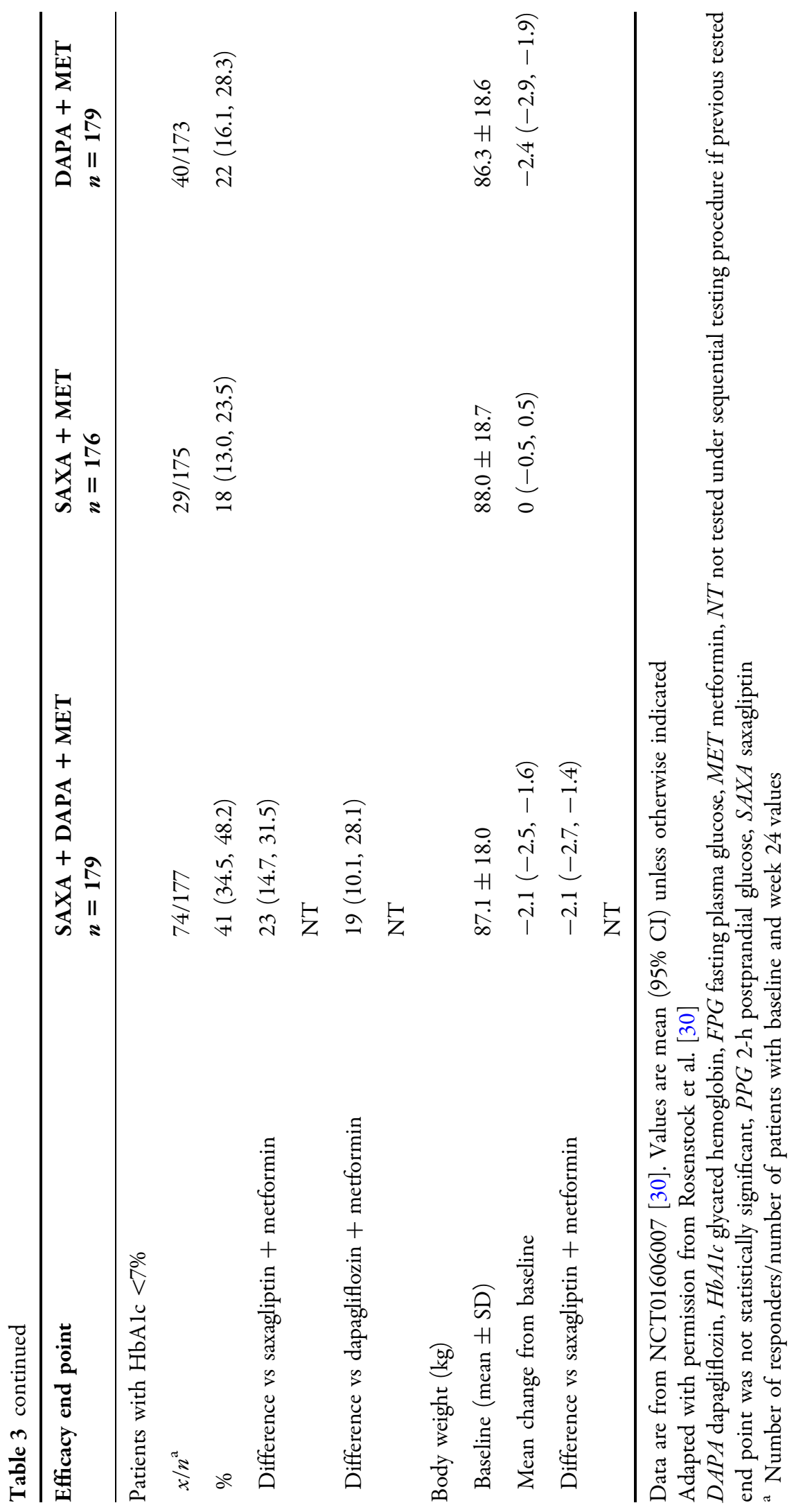


and $5 \mathrm{mg} /$ day, respectively, compared with $-0.2 \%$ with placebo [37]. The reductions in FPG and PPG with saxagliptin vs placebo were also sustained. At 76 weeks, a greater proportion of patients in the placebo group (44.0\%) required rescue medication or were discontinued for insufficient efficacy compared with the saxagliptin $2.5-\mathrm{mg}$ (35.9\%) and 5-mg (24.7\%) groups. Adverse events (AEs) related to treatment were similar across the saxagliptin and placebo groups (24.6-29.0\%).

In another long-term extension study, the changes from baseline in HbA1c after 76 weeks of treatment with saxagliptin 2.5 and $5 \mathrm{mg}$ /day add-on to glyburide compared with placebo add-on to uptitrated glyburide were $0.11 \%$, $0.03 \%$, and $0.69 \%$, respectively. The differences in change from baseline in HbA1c at 76 weeks between saxagliptin and uptitrated glyburide $(-0.63 \%$ and $-0.75 \%$ for 2.5 and $5 \mathrm{mg} /$ day, respectively) were similar to those seen at 24 weeks $(-0.62 \%$ and $-0.72 \%$, respectively). The proportions of patients achieving $\mathrm{HbA} 1 \mathrm{c}$ at 76 weeks were $11.0 \%$, $9.6 \%$, and $5.3 \%$ for saxagliptin $2.5,5 \mathrm{mg}$ /day, and uptitrated glyburide. Kaplan-Meier estimates of the proportion of patients discontinued or rescued for lack of glycemic control by week 76 were $74 \%, 71 \%$, and $87 \%$ for saxagliptin 2.5, $5 \mathrm{mg} /$ day, and uptitrated glyburide. Frequencies of AEs and hypoglycemia were similar across treatment groups [38].

The noninferiority of saxagliptin $5 \mathrm{mg}$ /day add-on vs glipizide add-on to metformin observed at 52 weeks of treatment [29] was sustained following an additional 52 weeks of treatment [39]. Change from baseline in HbA1c at 104 weeks was $-0.41 \%$ with saxagliptin vs $-0.35 \%$ with glipizide, and $23 \%$ of patients in each treatment group achieved HbA1c $<7 \%$. Over the course of the study, body weight decreased with saxagliptin $(-1.5 \mathrm{~kg})$ but increased with glipizide $(1.3 \mathrm{~kg})$. As was seen in the 52-week study, tenfold more patients reported a hypoglycemic event with glipizide $(38.4 \%)$ than with saxagliptin (3.5\%). With saxagliptin, $19.4 \%$ of patients achieved HbA1c $<7 \%$ with no weight gain or hypoglycemia, compared with $8.7 \%$ of patients receiving glipizide. Excluding hypoglycemia, the overall incidence of AEs and serious AEs (SAEs) was similar between treatment groups.

\section{Older Patients}

In the US, the prevalence of diabetes (diagnosed and undiagnosed) in individuals $\geq 65$ years of age $(25.9 \%)$ is almost 3 times higher than that in the general population (9.3\%) [2]. Because of the low risk of hypoglycemia and general lack of AEs associated with DPP-4 inhibitors, they may be especially useful for older patients [40].

A post hoc analysis of data pooled from five 24-week, placebo-controlled trials of saxagliptin and a separate analysis of initial combination therapy of saxagliptin plus metformin vs metformin monotherapy assessed the safety and efficacy of saxagliptin in older patients ( $\geq 65$ years) with T2DM [41]. At 24 weeks, the differences in adjusted mean changes from baseline in HbA1c with saxagliptin 2.5 and $5 \mathrm{mg}$ /day vs placebo were similar in patients $\geq 65$ years of age $(-0.60 \%$ and $-0.55 \%$, respectively) compared with those $<65$ years of age $(-0.56 \%$ and $-0.67 \%)$. In addition, the changes from baseline in FPG and 120-min PPG compared with placebo were similar for the 2 age groups. The proportions of patients achieving HbA1c $<7 \%$ at 24 weeks for saxagliptin 2.5 and $5 \mathrm{mg}$ /day were $37.8 \%$ and $44.9 \%$ ( $16.9 \%$ with placebo) in the $\geq 65$ years group and $32.5 \%$ and $34.5 \% \quad(19.0 \%$ with placebo) in the $<65$ years group. In the 
analysis of initial combination therapy of saxagliptin plus metformin vs metformin monotherapy, similar findings were observed, although the adjusted mean change from baseline in HbA1c with saxagliptin plus metformin combination vs metformin monotherapy was greater in patients $\geq 65$ years of age $(-1.22 \%)$ compared with those $<65$ years of age $(-0.53 \%)$. The overall incidence and types of AEs were similar for saxagliptin and comparators in patients $\geq 65$ and $<65$ years. In addition, hypoglycemic events did not vary between age categories.

\section{Patients with CV Disease or CV Risk Factors}

$\mathrm{CV}$ disease is highly prevalent in individuals with diabetes and accounts for most deaths in patients with T2DM [9, 42]. The efficacy and safety of saxagliptin were assessed in a post hoc analysis of patients with T2DM and CV disease or $\mathrm{CV}$ risk factors pooled from 5 randomized controlled trials [43]. Data from patients who received placebo or saxagliptin $5 \mathrm{mg}$ /day were analyzed by 4 criteria at baseline: (1) history vs no history of CV disease; (2) $\leq 1$ vs $\geq 2 \mathrm{CV}$ risk factors (hypertension, dyslipidemia, smoking, or family history of CV disease); (3) use vs no use of statins; and (4) hypertension vs no hypertension. In all subgroups, the change in HbA1c was greater with saxagliptin than with placebo (difference vs placebo, range $-0.62 \%$ to $-0.73 \%)$. There was no evidence for a treatment-by-subgroup interaction for any of the baseline criteria. Similar results were obtained for FPG and PPG. Moreover, the proportion of patients achieving HbA1c $<7 \%$ with saxagliptin was similar among patients with (range, 37.6-43.6\%) and without (34.3-35.5\%) CV disease, CV risk factors, hypertension, or use of statins. Similar rates and types of AEs were observed for saxagliptin and placebo regardless of $\mathrm{CV}$ disease or $\mathrm{CV}$ risk factor category [43]. The incidence of reported hypoglycemia was similar across treatment and $\mathrm{CV}$ risk groups (6.2-11.2\%). Incidence of confirmed hypoglycemia was $<1 \%$, except for patients with $\mathrm{CV}$ disease history receiving placebo $(2.1 \%)$.

\section{Overall Summary of Efficacy}

Results from these clinical trials demonstrate that saxagliptin is effective in improving glycemic control in a broad range of patients, including those early in the course of their disease as well as those with more advanced disease. In a preliminary analysis, baseline patient characteristics most closely associated with a response to saxagliptin (HbA1c decrease $\geq 0.5 \%$ ) included higher HbA1c, higher HOMA-2 $\beta$, lower fasting insulin concentration, shorter T2DM duration, and male sex [44].

\section{Safety and Tolerability}

In clinical trials, saxagliptin was generally well tolerated, with the incidence of AEs and SAEs similar to placebo or comparator (Table 2). Across clinical trials, the most commonly reported AEs included nasopharyngitis, upper respiratory tract infection, diarrhea, urinary tract infection, and headache. Discontinuations from the clinical trials as a result of an AE or SAE were also infrequent with saxagliptin and similar to placebo or comparator (Table 2).

A post hoc pooled analysis evaluated AEs of special interest in 20 randomized phase 2 and 3 clinical trials of saxagliptin and a subset of 11 saxagliptin add-on to metformin trials [45]. AEs of special interest included those associated with antidiabetes medications in general and AEs associated with DPP-4 physiology, nonclinical safety data of DPP-4 inhibitors, the known safety profile of DPP-4 inhibitors and 
GLP-1 receptor agonists, and postmarketing data. Deaths, SAEs, and discontinuations for an $\mathrm{AE}$, events of special interest, which included gastrointestinal-related AEs, infections, hypersensitivity reactions, pancreatitis, skin lesions, lymphopenia, thrombocytopenia, hypoglycemia, bone fracture, severe cutaneous AEs, opportunistic infection, angioedema, malignancy, and worsening renal function, low platelet counts and elevated liver enzymes were evaluated. Incidence rates (IRs; number of patients with an event/total person-years of exposure) were calculated for each $\mathrm{AE}$ category. In both the 20-study pool and the add-on to metformin pool, IRs for deaths, SAEs, and discontinuations for an $\mathrm{AE}$ were similar with saxagliptin and placebo or comparator. In both pooled sets of data, IRs for pancreatitis, malignancy, and most other AEs of special interest were similar between treatment groups. The IRs in the 20-study pool were higher with saxagliptin vs placebo or comparator for bone fractures and hypersensitivity AEs.

Table 4 Cardiovascular outcomes in the saxagliptin assessment of vascular outcomes recorded in patients with diabetes mellitus trial (SAVOR)

\begin{tabular}{|c|c|c|c|c|}
\hline \multirow[t]{2}{*}{ End point } & \multicolumn{2}{|l|}{$N(\%)$} & \multirow{2}{*}{$\begin{array}{l}\text { Hazard ratio } \\
(95 \% \mathrm{CI})\end{array}$} & \multirow[t]{2}{*}{$P$ value } \\
\hline & $\begin{array}{l}\text { Saxagliptin } \\
(n=8280)\end{array}$ & $\begin{array}{l}\text { Placebo } \\
(n=8212)\end{array}$ & & \\
\hline Primary composite end point: & $613(7.3)$ & $609(7.2)$ & $1.00(0.89,1.12)$ & 0.99 \\
\hline \multicolumn{5}{|l|}{$\mathrm{CV}$ death, myocardial infarction, or stroke } \\
\hline Secondary composite end point: & $1059(12.8)$ & $1034(12.4)$ & $1.02(0.94,1.11)$ & 0.66 \\
\hline \multicolumn{5}{|l|}{$\begin{array}{l}\mathrm{CV} \text { death, myocardial infarction, stroke, hospitalization for } \\
\text { unstable angina, hospitalization for heart failure, or } \\
\text { hospitalization for coronary revascularization }\end{array}$} \\
\hline \multicolumn{5}{|l|}{ Individual components of composite end points: } \\
\hline Death from any cause & $420(4.9)$ & $378(4.2)$ & $1.11(0.96,1.27)$ & 0.15 \\
\hline $\mathrm{CV}$ death & $269(3.2)$ & $260(2.9)$ & $1.03(0.87,1.22)$ & 0.72 \\
\hline Myocardial infarction & $265(3.2)$ & $278(3.4)$ & $0.95(0.80,1.12)$ & 0.52 \\
\hline Ischemic stroke & $157(1.9)$ & $141(1.7)$ & $1.11(0.88,1.39)$ & 0.38 \\
\hline Hospitalization for unstable angina & $97(1.2)$ & $81(1.0)$ & $1.19(0.89,1.60)$ & 0.24 \\
\hline Hospitalization for heart failure & $289(3.5)$ & $228(2.8)$ & $1.27(1.07,1.51)$ & 0.007 \\
\hline Hospitalization for coronary revascularization & $423(5.2)$ & $459(5.6)$ & $0.91(0.80,1.04)$ & 0.18 \\
\hline $\begin{array}{l}\text { Doubling of creatinine level, initiation of dialysis, renal } \\
\text { transplantation, or creatinine }>6.0 \mathrm{mg} / \mathrm{dL}\end{array}$ & $194(2.2)$ & $178(2.0)$ & $1.08(0.88,1.32)$ & 0.46 \\
\hline Hospitalization for hypoglycemia & $53(0.6)$ & $43(0.5)$ & $1.22(0.82,1.83)$ & 0.33 \\
\hline
\end{tabular}

Event rates and percentages are 2-year Kaplan-Meier estimates Adapted with permission from Scirica et al. [46]

$C V$ cardiovascular 


\section{Safety}

The prospectively designed CV outcomes trial, Saxagliptin Assessment of Vascular Outcomes Recorded in Patients With Diabetes Mellitus (SAVOR; ClinicalTrials.gov identifier, NCT01107886), assessed the CV safety of saxagliptin 5 or $2.5 \mathrm{mg} /$ day (in patients with an estimated glomerular filtration rate $\leq 50 \mathrm{~mL} /$ min) vs placebo in patients $(N=16,492)$ with T2DM and established CV disease or with multiple risk factors for $\mathrm{CV}$ disease [46]. Patient mean age was 65 years, median duration of T2DM was 10.3 years, and baseline mean HbA1c was $8.0 \%$. Concomitant medications at baseline included renin-angiotensin system (RAS) blockers (angiotensin-converting enzyme inhibitors or angiotensin II receptor antagonists, 82\%), $\beta$-blockers (62\%), and insulin therapy (41\%). Patients were followed for a median of 2.1 years. The primary end point was a composite of $\mathrm{CV}$ death, nonfatal MI, or nonfatal stroke. The secondary composite end point included the primary end point components plus hospitalization for heart failure, hospitalization for coronary revascularization, or hospitalization for unstable angina. The primary end point occurred in a similar proportion of patients receiving saxagliptin $(7.3 \%)$ or placebo (7.2\%) [hazard ratio (HR; 95\% CI) for saxagliptin vs placebo, 1.00 (0.89, 1.12); $\quad P=0.99 ; \quad$ Table 4$]$, indicating that saxagliptin neither increased nor decreased the rate of ischemic events in these patients. Results were similar for the secondary end point $(12.8 \%$ vs $12.4 \%$; HR, 1.02 ; 95\% CI, 0.94, 1.11; $P=0.66)$. However, in an analysis of the individual components of the secondary end point, more patients in the saxagliptin group than in the placebo group were hospitalized for heart failure [3.5\% vs $2.8 \%$; HR, 1.27 (1.07,
1.51); $P=0.007]$. The increased risk of hospitalization for heart failure with saxagliptin was highest among patients with a high overall risk of heart failure (previous heart failure, chronic kidney disease, or elevated concentrations of N-terminal pro-brain natriuretic peptide) [47]. The relative risk of hospitalization for heart failure with saxagliptin was similar in patients with baseline estimated glomerular filtration rates $>50,30$ to 50 , and $<30 \mathrm{~mL} / \mathrm{min} / 1.73 \mathrm{~m}^{2}$ [48].

The reason for the increase in hospitalization for heart failure with saxagliptin in SAVOR is not clear [46]. Recent meta-analyses of randomized clinical trials [49] and a US insurance claims database [50] suggest that DPP-4 inhibitors may be associated with an increased risk of heart failure in patients with T2DM, [49] or with an increased risk of heart failure-associated hospitalization in patients with T2DM and preexisting heart failure [50]. However, other observational studies suggest no increased risk of hospitalization for heart failure with saxagliptin compared with sitagliptin [51] or with DPP-4 inhibitors as a class compared with other antidiabetes drugs [51, 52].

Two other CV outcomes trials with DPP-4 inhibitors have completed. In the EXamination of cAardiovascular outcoMes with alogliptIN vs standard of carE in patients with T2DM and acute coronary syndrome (EXAMINE; ClinicalTrials.gov identifier, NCT00968708) [53], patients with T2DM who had a recent acute coronary syndrome $(N=5380)$ were randomized to alogliptin or placebo. Concomitant medications at baseline included RAS blockers (82\%), $\beta$-blockers (82\%), and insulin (30\%). Median exposure was 18 months. The primary composite end point of $\mathrm{CV}$ death, nonfatal MI, or nonfatal stroke occurred in similar proportions of patients randomized to alogliptin (11.3\%) or placebo 
(11.8\%; HR, 0.96; $P=0.32$ ). In a prespecified analysis of exploratory end points from EXAMINE, the proportion of patients hospitalized for heart failure was similar between the alogliptin and placebo groups [3.1\% vs 2.9\%; HR, 1.07 (95\% CI; 0.79, 1.46); $P=0.657$ [ [54]. Additional results from a post hoc subgroup analysis demonstrated no increased risk for new or recurrent hospitalizations for heart failure in patients with heart failure at baseline treated with alogliptin (8.2\%) compared with placebo [8.5\%; HR, $1.00 \quad(95 \% \quad \mathrm{CI}, \quad 0.71, \quad 1.42)$; $P=0.996]$. However, in patients without preexisting heart failure, an increased risk of hospitalization for heart failure was found in alogliptin-treated patients (2.2\%) compared with patients receiving placebo [1.3\%; HR, 1.76 (95\% CI, 1.07, 2.90); $P=0.026$ ] [54]. In the Trial Evaluating Cardiovascular Outcomes with Sitagliptin (TECOS; ClinicalTrials.gov identifier, NCT00790205) [55], patients with T2DM and a history of major coronary artery disease, ischemic cerebrovascular disease, or atherosclerotic arterial disease $(N=14,671)$ were randomized to sitagliptin or placebo. Concomitant medications at baseline included RAS blockers (79\%), $\beta$-blockers (64\%), and insulin therapy (23\%). The median follow-up was 3 years. The primary composite end point of CV death, nonfatal MI, nonfatal stroke, or hospitalization for unstable angina occurred in $11.4 \%$ of patients who were receiving sitagliptin and in $11.6 \%$ of patients receiving placebo [HR $\left(\begin{array}{llllll}95 \% & \text { CI } & 0.98 & (0.88, & 1.09\end{array}\right) \quad P<0.001$ for noninferiority and $0.98(0.89,1.08) P=0.65$ for superiority vs placebo]. There was no difference in the secondary composite end point of $\mathrm{CV}$ death, nonfatal MI, or nonfatal stroke between sitagliptin and placebo groups [HR (95\% CI) $0.99(0.89,1.11) ; P<0.001$ for noninferiority; HR (95\% CI) 0.99 (0.89, 1.10); $P=0.84$ for superiority]. In addition, there was no difference between the groups in the rate of hospitalization for heart failure [HR (95\% CI) $1.00(0.83,1.20) ; P=0.98]$, death from any cause [HR (95\% CI) $1.01(0.90,1.14) ; P=0.88$ ], or other prespecified end points.

Two additional ongoing CV outcomes trials with linagliptin [56] may help clarify whether individual DPP-4 inhibitors or DPP-4 inhibitors as a class increase the risk for heart failure hospitalizations.

\section{Pancreatitis}

The potential association of incretin-based therapies with pancreatitis and pancreatic cancer has been widely debated [57-59]. Although some studies have reported an increased risk for pancreatitis or pancreatic cancer with GLP-1 receptor agonists and DPP-4 inhibitors [60, 61], other studies have not supported this conclusion $[62,63]$. In the SAVOR trial, adjudication-confirmed cases of pancreatitis occurred in a similar proportion of patients receiving saxagliptin $(0.29 \%)$ or placebo [0.26\%; HR (95\% CI) $1.13(0.63,2.06) ; P=0.77]$ [64]. Pancreatic cancer was reported in 5 patients in the saxagliptin-treated group and in 12 in the placebo group [HR (95\% CI) $0.42(0.13,1.12)$; $P=0.09]$. Therefore, the results from the SAVOR trial suggest that the risk of pancreatitis was low with saxagliptin and not different from placebo, and there was no signal of an increased risk of pancreatic cancer over a median follow-up of 2.1 years.

\section{CONCLUSIONS}

Published clinical data on saxagliptin reflect a broad range of patients with T2DM who 
prescribers see on a daily basis, such as patients early in the course of their disease for whom diet and exercise alone were not effective in reducing hyperglycemia, patients not achieving adequate control with metformin or other classes of antidiabetes agents, patients receiving insulin, older patients, and patients with $\mathrm{CV}$ risk factors. In patients with T2DM, treatment with saxagliptin resulted in significantly improved glycemic control when used as monotherapy or when added to other antidiabetes agents including metformin, a sulfonylurea, a TZD, insulin, or a sodium-glucose cotransporter 2 inhibitor. Across clinical trials, the overall AE profile of saxagliptin was similar to that of placebo; treatment with saxagliptin was associated with a low risk of hypoglycemia and a neutral effect on weight. The improvement in glycemic control seen at 24 weeks of treatment with saxagliptin was maintained for up to 4 years, and the long-term overall safety and tolerability of saxagliptin were similar to that in shorter-term studies. Saxagliptin improved glycemic control in older patients as well as in patients with $\mathrm{CV}$ disease or with $\mathrm{CV}$ disease risk factors. In a large $\mathrm{CV}$ outcomes study that enrolled patients with established $\mathrm{CV}$ disease or with multiple $\mathrm{CV}$ disease risk factors (SAVOR), saxagliptin did not increase or decrease the rate of ischemic events. However, the rate of hospitalization for heart failure was increased with saxagliptin compared with placebo in SAVOR. Thus, the overall positive clinical profile for saxagliptin needs to be tempered by the observation of an increased risk of hospitalization for heart failure observed in SAVOR. The reasons for this increase in hospitalizations for heart failure are not clear and no specific mechanism has been identified. Additional evaluation of heart failure events and the potential mechanisms involved are needed to provide additional data on how best to manage patients with T2DM who are also at risk for heart failure.

\section{ACKNOWLEDGMENTS}

The article processing charges and open access fee for this publication were funded by AstraZeneca LP (Wilmington, DE). Medical writing support was provided by Richard Edwards, PhD, and Janet Matsuura, PhD (Complete Healthcare Communications, Inc., Chadds Ford, PA) and was funded by AstraZeneca LP. The named author meets the International Committee of Medical Journal Editors (ICMJE) criteria for authorship for this manuscript, takes responsibility for the integrity of the work as a whole, and has given final approval for the version to be published.

Disclosures. R J. has served on the speaker's bureau for AstraZeneca, Merck, Takeda, Novo Nordisk, and Eli Lilly and has received clinical research support from Novo Nordisk, Sanofi, Takeda and Janssen.

Compliance with ethics guidelines. This article is based on previously conducted studies and does not involve any new studies of human or animal subjects performed by the author.

Open Access. This article is distributed under the terms of the Creative Commons Attribution-NonCommercial 4.0 International License (http://creativecommons.org/licenses/ by-nc/4.0/), which permits any noncommercial use, distribution, and reproduction in any medium, provided you give appropriate credit to the original author(s) and the source, provide a link to the Creative Commons license, and indicate if changes were made. 


\section{REFERENCES}

1. International Diabetes Federation. IDF Diabetes Atlas. Available at: http://www.idf.org/sites/default/files/ Atlas-poster-2014_EN.pdf. Accessed 6 Nov 2015.

2. Centers for Disease Control and Prevention. National diabetes statistics report: estimates of diabetes and its burden in the United States, 2014. Available at: http://www.cdc.gov/diabetes/pubs/ statsreport14/national-diabetes-report-web.pdf. Accessed 6 Nov 2015.

3. American Diabetes Association. Standards of medical care in diabetes-2015. Diabetes Care. 2015;38:S88-9.

4. McCarthy MI. Genomics, type 2 diabetes, and obesity. N Engl J Med. 2010;363:2339-50.

5. Valdez R, Yoon PW, Liu T, Khoury MJ. Family history and prevalence of diabetes in the US population: the 6-year results from the National Health and Nutrition Examination Survey (1999-2004). Diabetes Care. 2007;30:2517-22.

6. Ali MK, Bullard KM, Saaddine JB, Cowie CC, Imperatore G, Gregg EW. Achievement of goals in US diabetes care, 1999-2010. N Engl J Med. 2013;368:1613-24.

7. Stark Casagrande S, Fradkin JE, Saydah SH, Rust KF, Cowie CC. The prevalence of meeting A1C, blood pressure, and LDL goals among people with diabetes, 1988-2010. Diabetes Care. 2013;36:2271-2279.

8. Fowler M. Microvascular and macrovascular complications of diabetes. Clin Diabetes. 2008;26:77-82.

9. Centers for Disease Control and Prevention. National diabetes fact sheet, 2011: national estimates and general information on diabetes and prediabetes in the United States. US Department of Health and Human Services, Centers for Disease Control and Prevention. Available at: http://www. cdc.gov/diabetes/pubs/pdf/ndfs_2011.pdf. Accessed 6 Nov 2015.

10. Kahn SE, Cooper ME, Del Prato S. Pathophysiology and treatment of type 2 diabetes: perspectives on the past, present, and future. Lancet. 2014;383:1068-83.

11. DeFronzo R. Banting lecture. From the triumvirate to the ominous octet: a new paradigm for the treatment of type 2 diabetes mellitus. Diabetes. 2009;58:773-95.

12. Elrick H, Stimmler L, Hlad CJ Jr, Arai Y. Plasma insulin response to oral and intravenous glucose administration. J Clin Endocrinol Metab. 1964;24:1076-82.

13. Drucker DJ. The biology of incretin hormones. Cell Metab. 2006;3:153-65.

14. Nauck MA, Baller B, Meier JJ. Gastric inhibitory polypeptide and glucagon-like peptide-1 in the pathogenesis of type 2 diabetes. Diabetes. 2004;53:S190-6.

15. Drucker DJ, Nauck MA. The incretin system: glucagon-like peptide-1 receptor agonists and dipeptidyl peptidase- 4 inhibitors in type 2 diabetes. Lancet. 2006;368:1696-705.

16. Frederich R, McNeill R, Berglind N, Fleming D, Chen R. The efficacy and safety of the dipeptidyl peptidase-4 inhibitor saxagliptin in treatment-naive patients with type 2 diabetes mellitus: a randomized controlled trial. Diabetol Metab Syndr. 2012;4:36.

17. Kumar KMP, Jain SM, Tou C, Schützer K-M. Saxagliptin as initial therapy in treatment-naive Indian adults with type 2 diabetes mellitus inadequately controlled with diet and exercise alone: a randomized, double-blind, placebo-controlled, phase IIIb clinical study. Int J Diabetes Dev Ctries. 2014;34:201-9.

18. Pan CY, Yang W, Tou C, Gause-Nilsson I, Zhao J. Efficacy and safety of saxagliptin in drug-naive Asian patients with type 2 diabetes mellitus: a randomized controlled trial. Diabetes Metab Res Rev. 2012;28:268-75.

19. Rosenstock J, Aguilar-Salinas C, Klein E, et al. Effect of saxagliptin monotherapy in treatment-naive patients with type 2 diabetes. Curr Med Res Opin. 2009;25:2401-11.

20. Wallace TM, Levy JC, Matthews DR. Use and abuse of HOMA modeling. Diabetes Care. 2004;27:1487-95.

21. DeFronzo R, Hissa MN, Garber AJ, et al. Once-daily saxagliptin added to metformin provides sustained glycemic control and is well tolerated over 102 weeks in patients with type 2 diabetes. Diabetes. 2009;58:547-P.

22. Hermans MP, Delibasi T, Farmer I, et al. Effects of saxagliptin added to sub-maximal doses of metformin compared with uptitration of metformin in type 2 diabetes: the PROMPT study. Curr Med Res Opin. 2012;28:1635-45.

23. Yang W, Pan CY, Tou C, Zhao J, Gause-Nilsson I. Efficacy and safety of saxagliptin added to metformin in Asian people with type 2 diabetes 
mellitus: a randomized controlled trial. Diabetes Res Clin Pract. 2011;94:217-24.

24. Jadzinsky M, Pfutzner A, Paz-Pacheco E, Xu Z, Allen $\mathrm{E}$, Chen R. Saxagliptin given in combination with metformin as initial therapy improves glycaemic control in patients with type 2 diabetes compared with either monotherapy: a randomized controlled trial. Diabetes Obes Metab. 2009;11:611-22.

25. Hollander P, Li J, Allen E, Chen R. CV181-013 Investigators. Saxagliptin added to a thiazolidinedione improves glycemic control in patients with type 2 diabetes and inadequate control on thiazolidinedione alone. J Clin Endocrinol Metab. 2009;94:4810-9.

26. Chacra AR, Tan GH, Apanovitch A, et al. Saxagliptin added to a submaximal dose of sulphonylurea improves glycaemic control compared with uptitration of sulphonylurea in patients with type 2 diabetes: a randomised controlled trial. Int J Clin Pract. 2009;63:1395-406.

27. Barnett AH, Charbonnel B, Donovan M, Fleming D, Chen R. Effect of saxagliptin as add-on therapy in patients with poorly controlled type 2 diabetes on insulin alone or insulin combined with metformin. Curr Med Res Opin. 2012;28:513-23.

28. Moses RG, Kalra S, Brook D, et al. A randomized controlled trial of the efficacy and safety of saxagliptin as add-on therapy in patients with type 2 diabetes and inadequate glycaemic control on metformin plus a sulphonylurea. Diabetes Obes Metab. 2014;16:443-50.

29. Göke B, Gallwitz B, Eriksson J, Hellqvist A, Gause-Nilsson I. Saxagliptin is non-inferior to glipizide in patients with type 2 diabetes mellitus inadequately controlled on metformin alone: a 52-week randomised controlled trial. Int J Clin Pract. 2010;64:1619-31.

30. Rosenstock J, Hansen L, Zee P, et al. Dual add-on therapy in type 2 diabetes poorly controlled with metformin monotherapy: a randomized double-blind trial of saxagliptin plus dapagliflozin addition vs single addition of saxagliptin or dapagliflozin to metformin. Diabetes Care. 2015;38:376-83.

31. Del Prato S, Camisasca R, Wilson C, Fleck P. Durability of the efficacy and safety of alogliptin compared with glipizide in type 2 diabetes mellitus: a 2-year study. Diabetes Obes Metab. 2014;16:1239-46.

32. Gallwitz B, Rosenstock J, Rauch T, et al. 2-year efficacy and safety of linagliptin compared with glimepiride in patients with type 2 diabetes inadequately controlled on metformin: a randomised, double-blind, non-inferiority trial. Lancet. 2012;380:475-83.

33. Matthews DR, Dejager S, Ahren B, et al. Vildagliptin add-on to metformin produces similar efficacy and reduced hypoglycaemic risk compared with glimepiride, with no weight gain: results from a 2-year study. Diabetes Obes Metab. 2010;12:780-9.

34. Seck T, Nauck M, Sheng D, et al. Safety and efficacy of treatment with sitagliptin or glipizide in patients with type 2 diabetes inadequately controlled on metformin: a 2-year study. Int J Clin Pract. 2010;64:562-76.

35. Rosenstock J, Gross JL, Aguilar-Salinas C, et al. Long-term 4-year safety of saxagliptin in drug-naive and metformin-treated patients with type 2 diabetes. Diabet Med. 2013;30:1472-6.

36. Pfützner A, Paz-Pacheco E, Allen E, Frederich B, Chen R, for the CV181039 Investigators. Initial combination therapy with saxagliptin and metformin provides sustained glycaemic control and is well tolerated for up to 76 weeks. Diabetes Obes Metab. 2011;13:567-76.

37. Hollander PL, Li J, Frederich R, Allen E, Chen R. CV 181013 Investigators. Safety and efficacy of saxagliptin added to thiazolidinedione over 76 weeks in patients with type 2 diabetes mellitus. Diab Vasc Dis Res. 2011;8:125-35.

38. Chacra AR, Tan GH, Ravichandran S, List J, Chen R. CV181040 Investigators. Safety and efficacy of saxagliptin in combination with submaximal sulphonylurea vs up-titrated sulphonylurea over 76 weeks. Diab Vasc Dis Res. 2011;8:150-9.

39. Goke B, Gallwitz B, Eriksson JG, Hellqvist A, Gause-Nilsson I. Saxagliptin vs. glipizide as add-on therapy in patients with type 2 diabetes mellitus inadequately controlled on metformin alone: long-term (52-week) extension of a 52-week randomised controlled trial. Int $\mathrm{J}$ Clin Pract. 2013;67:307-16.

40. International Diabetes Federation. Managing older people with type 2 diabetes. Available at: http:// www.idf.org/guidelines/managing-older-peopletype-2-diabetes. Accessed 6 Nov 2015.

41. Karyekar CS, Ravichandran S, Allen E, Fleming D, Frederich R. Tolerability and efficacy of glycemic control with saxagliptin in older patients (aged $\geq 65$ years) with inadequately controlled type 2 diabetes mellitus. Clin Interv Aging. 2013;8:419-30.

42. Laakso M. Cardiovascular disease in type 2 diabetes from population to man to mechanisms: the Kelly West Award Lecture 2008. Diabetes Care. 2010;33:442-9. 
43. Cook W, Bryzinski B, Slater J, Frederich R, Allen E. Saxagliptin efficacy and safety in patients with type 2 diabetes mellitus and cardiovascular disease history or cardiovascular risk factors: results of a pooled analysis of phase 3 clinical trials. Postgrad Med. 2013;125:145-54.

44. Hirshberg B, Leibowitz G, Iqbal N, Cook W, Wei C, Sjostrand M. Saxagliptin responder analysis: a pooled analysis of 5 clinical trials (abstract). Endocr Pract. 2014;20:1A-44A.

45. Hirshberg B, Parker A, Edelberg H, Donovan M, Iqbal N. Safety of saxagliptin: events of special interest in 9156 patients with type 2 diabetes mellitus. Diabetes Metab Res Rev. 2014;30:556-69.

46. Scirica BM, Bhatt DL, Braunwald E, et al. Saxagliptin and cardiovascular outcomes in patients with type 2 diabetes mellitus. $\mathrm{N}$ Engl J Med. 2013;369:1317-26.

47. Scirica BM, Braunwald E, Raz I, et al. Heart failure, saxagliptin, and diabetes mellitus: observations from the SAVOR-TIMI 53 randomized trial. Circulation. 2014;130:1579-88.

48. Udell JA, Bhatt DL, Braunwald E, et al. Saxagliptin and cardiovascular outcomes in patients with type 2 diabetes and moderate or severe renal impairment: observations from the SAVOR-TIMI 53 trial. Diabetes Care. 2015;38:696-705.

49. Monami M, Dicembrini I, Mannucci E. Dipeptidyl peptidase-4 inhibitors and heart failure: a meta-analysis of randomized clinical trials. Nutr Metab Cardiovasc Dis. 2014;24:689-97.

50. Weir DL, McAlister FA, Senthilselvan A, Minhas-Sandhu JK, Eurich DT. Sitagliptin use in patients with diabetes and heart failure: a population-based retrospective cohort study. JACC Heart Fail. 2014;2:573-82.

51. Fu AZ, Johnston S, Sheehan J, et al. Risk of hospitalization for heart failure with dipeptidyl peptidase- 4 inhibitors vs sulfonylureas and with saxagliptin vs sitagliptin in a US claims database. Diabetes. 2015;64:LB42.

52. Giorda CB, Picariello R, Tartaglino B, et al. Hospitalisation for heart failure and mortality associated with dipeptidyl peptidase 4 (DPP-4) inhibitor use in an unselected population of subjects with type 2 diabetes: a nested case-control study. BMJ Open. 2015;5:e007959.

53. White WB, Cannon CP, Heller SR, et al. Alogliptin after acute coronary syndrome in patients with type 2 diabetes. N Engl J Med. 2013;369:1327-35.
54. Zannad F, Cannon C, Cushman WC, et al. Heart failure and mortality outcomes in patients with type 2 diabetes taking alogliptin vs placebo in EXAMINE: a multicentre, randomised, double-blind trial. Lancet. 2015;385:2067-76.

55. Green JB, Bethel MA, Armstrong PW, et al. Effect of sitagliptin on cardiovascular outcomes in type 2 diabetes. N Engl J Med. 2015;373:232-42.

56. Rosenstock J, Marx N, Kahn SE, et al. Cardiovascular outcome trials in type 2 diabetes and the sulphonylurea controversy: rationale for the active-comparator CAROLINA trial. Diab Vasc Dis Res. 2013;10:289-301.

57. Butler PC, Elashoff M, Elashoff R, Gale EA. A critical analysis of the clinical use of incretin-based therapies: are the GLP-1 therapies safe? Diabetes Care. 2013;36:2118-25.

58. Nauck MA. A critical analysis of the clinical use of incretin-based therapies: the benefits by far outweigh the potential risks. Diabetes Care. 2013;36:2126-32.

59. Egan AG, Blind E, Dunder K, et al. Pancreatic safety of incretin-based drugs-FDA and EMA assessment. N Engl J Med. 2014;370:794-7.

60. Elashoff M, Matveyenko AV, Gier B, Elashoff R, Butler PC. Pancreatitis, pancreatic, and thyroid cancer with glucagon-like peptide-1-based therapies. Gastroenterology. 2011;141:150-6.

61. Singh S, Chang HY, Richards TM, Weiner JP, Clark JM, Segal JB. Glucagonlike peptide 1-based therapies and risk of hospitalization for acute pancreatitis in type 2 diabetes mellitus: a population-based matched case-control study. JAMA Intern Med. 2013;173:534-9.

62. Engel SS, Round E, Golm GT, Kaufman KD, Goldstein BJ. Safety and tolerability of sitagliptin in type 2 diabetes: pooled analysis of 25 clinical studies. Diabetes Ther. 2013;4:119-45.

63. Li L, Shen J, Bala MM, et al. Incretin treatment and risk of pancreatitis in patients with type 2 diabetes mellitus: systematic review and meta-analysis of randomised and non-randomised studies. BMJ. 2014;348:g2366.

64. Raz I, Bhatt DL, Hirshberg B, et al. Incidence of pancreatitis and pancreatic cancer in a randomized controlled multicenter trial (SAVOR-TIMI 53) of the dipeptidyl peptidase-4 inhibitor saxagliptin. Diabetes Care. 2014;37:2435-41. 